\title{
EMOTIONAL INTELLIGENCE AS PART OF THE STRATEGIC DEVELOPMENT AND MANAGEMENT STYLE IN THE PRE-HIGH EDUCATIONAL SYSTEM IN ALBANIA Nada Kallciu ${ }^{1}$, Rovena Cakaj ${ }^{2}$, Bruna Papa ${ }^{3}$
}

\begin{abstract}
In today's modern world, emotional intelligence (EI) has a strong connection in the work environment and it is considered to be one of the key factors in the well-functioning of institutions, especially of educational ones.

The main aim of this study is to identify, whether the directors of the schools of the pre-high educational system in Albania are aware of the concept of emotional intelligence, are trained and if they implement it in their leading style, in order to achieve an overall success in schools. The study also aims to identify the differences between new and senior principals in using EI.

The research methodology is quantitative, 183 questionnaires were filled in by teachers in 11 different schools of the pre high educational institutions in Tirana.

The instrument used consists of 40 standard statements that cover all five characteristics of the emotional intelligence: selfawareness, self-control, motivation, empathy and social skills, by analyzing the level of agreement in a 1-5 Likert scale.

The study has shown that principals and teachers of the pre high educational system in Albania have no knowledge on emotional intelligence and as a result they do not implement it. The principals do possess some elements of emotional intelligence as a part of their soft skills, but they are not aware of them and do not use them in increasing the teachers' work satisfaction.

Also, there is no difference in the usage of emotional intelligence between young and senior principals, apart from the fact that the seniors have better developed soft skills. This would help them to come closer to the characteristics of emotional intelligence.

The results of the study imply some recommendations for policy makers, school's principals and mentor teachers in increasing the use of emotional intelligence in the pre high educational system in Albania. The results confirm the necessity to train the principals about the latest news in the field of education, ethics, communication and leadership with a focus on raising leadership within the focus of Emotional Intelligence. The ministry of Education, Sport and Youth should design policies for the professional development of leaders and teachers in accordance with new management strategies such as emotional intelligence.
\end{abstract}

UDC classification number: 37.07:005.33, DOI: https://doi.org/10.12955/pss.v1.58

Keywords: emotional intelligence, strategic leadership, pre high educational system, soft skills, teachers.

\section{Introduction}

Education is one of the most important areas in every society and system. The values, the tradition, the cultural heritage and knowledge of a nation are transmitted from one generation to another, through the education of its members.

Education is one of the areas that not only leads societies but is also strongly influenced by them and social change.

Even in our country, in the recent years, there is a tendency for changes in legislation, curriculum, infrastructure etc. Educational institutions through politics are trying to adapt to the cultural, economic, social and technological changes that society offers today.

The goal

The main purpose of this study is to identify the presence and strategic use of emotional intelligence by school principals, to identify which category of directors use it the most, and to try to analyze the importance that IE has in leadership, in teachers' job satisfaction in the pre-university education system.

Introducing the problem

Recent years have been difficult for Albanian education. Being part of it, we often encounter unhappy teachers with the country's education policy, infrastructure, or incompetent leaders. During 2017, the Ministry of Education took an initiative testing all the principals and teachers in the public preuniversity education and the conclusion was that the principals had significantly lower scores than their school teachers. Given this and many studies made in the field of education that show that

\footnotetext{
${ }^{1}$ Faculty of Social Sciences, University of Tirana, Albania, nkallciu@gmail.com

${ }^{2}$ Faculty of Social Sciences, University of Tirana, Albania, rovenacakaj@live.com

${ }^{3}$ Faculty of Economy, University of Tirana, Albania, nickabruna@gmail.com
} 
dissatisfied teachers also have poor performance, and consequently students have lower scores, the question naturally arises: How can this situation be changed and who is responsible for the change?

According to one of the most well-known researchers in the field of education, Michael Fullan as well as other educational psychologists, teachers are responsible for change.

"Cultures change in a thousand small ways, not from dramatic announcements the offices of leaders. If we expect senior leaders to lead the changes, then we have understood nothing. To have any hope for the future that we want, we have to grant things our own direction" (Fullan, 2010).

In this perspective and in the current conditions of our education, changes in teachers can certainly make you a leader, and Emotional Intelligence is a more effective method, that is used nowadays and that can bring a change in human relationships. Emotional Intelligence with all its dimensions can be appropriated and learned in a way that success can be guaranteed. Therefore, this modest study aims to show whether school leaders know it and to highlight its importance in terms of the success of each school.

The main questions in this study are:

- Are school leaders in pre-university education aware of the existence of emotional intelligence?

- Is emotional intelligence part of the leadership strategy in Albanian schools?

- Do executives recognize the importance of emotional intelligence in the success of an organization?

- Are they trained on IE practices and ways?

- Who uses most IEs, more experienced executives or new executives?

\section{Literature review}

Studies and world literature emphases that all changes that can be made in the education sector depend on human resources, only the latter can change and improve it, contributing to the well-being of a society.

Given the many studies and contextual need in educational institutions, there is a need to focus on motivating human resources.

For a successful organization, employees are the most important factor. Employee management depends on the quality and the way they are led. Leadership is defined as a process that involves influencing a group to achieve common goals, a process where one person engages with others, increases the motivation and the morale of followers (Goleman et al., 2002).

Goleman et al. (2002) insist that modern leaders must communicate in a friendly manner, deliver a vision, be encouraging, helpful, innovative, and ready to collaborate in all levels of the organization. According to contemporary studies, all of these qualities are related to emotional intelligence as a key factor in an organization's performance.

Emotional intelligence: the strategy of success at work

The term emotional intelligence (EI) is first mentioned by Mayer and Salovey (1990), who defined emotional intelligence as "the ability to monitor the feelings and emotions of oneself and others as a function of guiding one's thinking and action" (Rathore, Chadha et al, 2017).

After several further studies, emotional intelligence was defined as the ability to perceive emotions, to understand the feeling related to emotions, and to manage them (Babu and Vaitla, 2013).

Emotional intelligence is a set of traits or abilities that help you recognize emotions, control them, motivate you, and at the same time understand and manage the emotions of others in order to deal with interpersonal relationships effectively. (Babu and Vaitla, 2013).

Mayer and Salovey (1997) suggest that people who are unable to control their feelings or impulses tend to show disabilities in human relationships, based on the fact that the essence of will and character is precisely the control of one's emotions.

Emotional intelligence is defined as the factor that has the potential to contribute to the creation of positive behaviors, attitudes, and outcomes. (Mayer and Salovey, 1997). 
Until 1990 the concept of EI mattered little in practice. Most studies referred to cognitive intelligence. Today, both forms of intelligence are given importance as they contribute to success. Studies have already focused on linking Emotional Intelligence and Leadership.

In a study conducted by Wong, (Babu and Vaitla, 2013) on the emotional intelligence of school principals and teacher satisfaction in Hong Kong, it was found that schoolteachers believe that the emotional intelligence of principals is important to their success. This study showed that success in school performance requires high levels of emotional intelligence, both for teachers and school leaders. It also demonstrated the importance of emotional intelligence and the need for policy development in the design of training programs to improve the emotional intelligence of teachers and school leaders.

Sy, Tram, and O'Hara (2006) conducted a survey of 187 food service employees from 9 different locations in the same restaurant to examine the correlation between emotional intelligence and job satisfaction. The study found that employees' emotional intelligence was positively associated with job satisfaction. Moreover, employees with low emotional intelligence had a more positive relationship with job satisfaction than those with high emotional intelligence. (Ngozi, Richards, Barnabas and Solomon, 2014).

From the foregoing and the suggestions that emerge applying to the principal's relationships with teachers, directors must be able to perceive the emotional climate in the organization, both at the individual and collective levels. Particularly when employees are trapped in a cycle of negative emotions, depression, and negative behaviors, noticing minor signs of emotional confusion such as mood swings or linear emotions, or abnormal behaviors for the person (e.g. drinking more, being associated more often) less than usual or behaviors not in line with the norms of the organization, here we can distinguish highly emotionally capable managers from those who are less capable in such tasks.

\section{Data and methodology}

In order to conduct this study, except the secondary data from the literature review, primary data were collected using the questionnaire survey method, which made it possible to measure the respondents' attitudes and the phenomenon itself.

The questionnaires were distributed in two ways: manually and by email. The presence in one of the tested institutions made it possible to pilot the core questions first and then the procedure of distributing the questionnaires and gathering information on time became possible. The purpose of the study and the confidentiality of the data were made clear to each of the test subjects. The questionnaire was voluntarily filled out by the survey participants.

The population of the study

The population of this study is the teachers of the pre-university education system in Albania. The study focused on 11 institutions in Tirana, out of which there were 2 general High Schools, 7 Primary and Lower Secondary Schools and 2 kindergartens.

The sample selected for the study consisted of 183 randomly selected teachers:

- 33 in kindergarten

- 150 others in base education

Focus group

2 target groups were implemented, that consist of teachers that belong to the Albanet Private School, located in the city of Tirana. The first group consists of teachers that have a work experience of longer than 15 years, while the second one of teachers that have an experience of less than 10 years. Some problems that concern the leadership, have been detected by using these two groups. Out of the two principals of the school, the one that has an experience of 20 years has been highly evaluated from the teachers, as she makes use of emotional intelligence and continuously motivates the staff, while the one that has only 5 years of experience is not able to use emotional intelligence and this has caused difficulties in the communication process with the staff and with its proper motivation

It has been noted that the principal that could not motivate and could not inspire by providing a role model, could not play the role of a motivator and did cause distress and unsatisfaction. The teachers that were directed by the later, did not show any work satisfaction and did not take any action towards 
the improving of their work. These teachers just minded their routine duties and were inclined to do, "only what they were paid for".

\begin{tabular}{|l|c|c|}
\hline \multicolumn{1}{|l|}{ Table 1: Number of employees for each school tested } \\
\hline & $\begin{array}{c}\text { Nr. of employees } \\
\text { participating in the survey }\end{array}$ & $\begin{array}{c}\text { Nr. of employees in } \\
\text { Tirana }\end{array}$ \\
\hline Albanët Kindergarden & 21 & 21 \\
\hline Universi Blu Kindergarden & 12 & 13 \\
\hline IJP Albanët & 23 & 45 \\
\hline IJP Nobel & 19 & 35 \\
\hline $\begin{array}{l}\text { At Zef PllumiPrimary and Lower Secondary } \\
\text { School }\end{array}$ & 13 & 33 \\
\hline $\begin{array}{l}\text { Kongresi i ManastiritPrimary and Lower } \\
\text { Secondary School }\end{array}$ & 12 & 33 \\
\hline $\begin{array}{l}\text { Dëshmorët e KombitPrimary and Lower } \\
\text { Secondary School }\end{array}$ & 10 & 43 \\
\hline $\begin{array}{l}\text { Vasil ShantoPrimary and Lower Secondary } \\
\text { School }\end{array}$ & 10 & 55 \\
\hline $\begin{array}{l}\text { Kristaq RamaPrimary and Lower Secondary } \\
\text { School }\end{array}$ & 9 & 30 \\
\hline IJP, Nobel High School & 8 & 35 \\
\hline Aleks Buda High School & 6 & 45 \\
\hline Total & 183 & 388 \\
\hline Soure: Aungr| & & \\
\hline
\end{tabular}

Source: Authors

On the other hand, the principal with many years of experience did show many of the attributes of a transforming leader. He conducted motivational conversations with the teachers, that inspired them towards achieving success. The teachers did show work satisfaction and were inclined to being more open in collaborating with one another, for the achievement of higher objectives and results.

Another significant change is reflected in their way of directing. The principal with less years of experience, shows the attributes of a simple manager that is only satisfied with performing their strict work and does require from the teachers, to do the same. She does not make use of the novelties and does not like change. The teachers directed by the later, do not embrace novelties and do not believe in collaboration towards the achievement of success.

The second leader trusts his teachers, motivates and often requests meetings with them on various issues. A great effort to encourage teachers to grow professionally was noticed. They require them to seek out ideas all the time and push for change. The principal often supports and motivates them to adopt new methods, techniques, and ways that affect school efficiency. They also attach great importance to their family problems, which makes them dear to the teachers. They say they come to school stress-free and work without harassing anyone, even though the headmaster is demanding, she does not make them feel bad.

What can be said from the direct observation and the questionnaires made, it is noted that none of the leaders uses IE as a strategy in achieving the objectives. But the younger principal unconsciously displays some soft skills that makes it easier for her to help build relationships. This direct observation preceded this study, taking place in several schools in Tirana.

The measuring instrument:

The measuring tool was a questionnaire containing 40 standardized questions, which included five characteristics of EI: self-awareness, self-control, motivation, social skills and empathy. (Goleman, 1995).

The questions were designed to test each respondent's assertions and attitudes about emotional leadership and intelligence. The questionnaire completion took approximately 20 minutes for each respondent and the data collection was extended to the January 2018 - April 2018.

Respondents were asked to maintain their views and opinions of their leaders. Respondents were asked to confirm whether or not they agreed with the views, opinions or assertions given. This way you can understand the way their leaders are doing and how much of the IE elements they use in leadership. 


\section{Results and discussion}

The study involved 183 employees, $76.7 \%$ female and $23.3 \%$ male. Most of the respondents had a high level of education and a master's degree. Participant age groups were mostly 30-39 years old, followed by 25-29 years old, 40 years old and finally 20-24 years old with a low percentage.

The heads of educational institutions in $70 \%$ of the schools surveyed, had an experience of $15-20$ years; while $30 \%$ of them have a working experience of 4-7 years. From the analyzed responses, no difference was observed between highly experienced and inexperienced executives.

\begin{tabular}{|c|c|c|c|}
\hline \multirow[b]{2}{*}{ Characteristic } & \multirow[b]{2}{*}{ Questions } & \multicolumn{2}{|c|}{ Answers in \% } \\
\hline & & I agree & I don't agree \\
\hline \multirow[b]{2}{*}{ Awareness } & 1. Overall they like themselves. & $65 \%$ & $35 \%$ \\
\hline & $\begin{array}{l}\text { 2. When make a decision they are } \\
\text { always sure that is the right one. }\end{array}$ & $65 \%$ & $35 \%$ \\
\hline \multirow{2}{*}{ Self-control } & $\begin{array}{l}\text { 1. Others admire them for their } \\
\text { calmness. }\end{array}$ & $30 \%$ & $70 \%$ \\
\hline & $\begin{array}{l}\text { 2. They often have a tendency to } \\
\text { change their minds. }\end{array}$ & $50 \%$ & $50 \%$ \\
\hline \multirow[t]{2}{*}{ Motivation } & $\begin{array}{l}\text { 1. They tend to see difficulties in every } \\
\text { opportunity instead of looking at } \\
\text { opportunity at every difficulty. }\end{array}$ & $75 \%$ & $25 \%$ \\
\hline & $\begin{array}{l}\text { 2. They usually find it difficult to keep } \\
\text { themselves motivated. }\end{array}$ & $50 \%$ & $50 \%$ \\
\hline \multirow{2}{*}{ Empathy } & $\begin{array}{l}\text { 1. They find it hard not to feel sad } \\
\text { when someone tells them something } \\
\text { bad. }\end{array}$ & $70 \%$ & $30 \%$ \\
\hline & $\begin{array}{l}\text { 2. It's not a problem for them to } \\
\text { understand others needs and desires. }\end{array}$ & $53 \%$ & $47 \%$ \\
\hline \multirow[b]{2}{*}{ Social Skills } & 1. They don't have social skills. & $30 \%$ & $70 \%$ \\
\hline & $\begin{array}{l}\text { 2. They think about their old friends } \\
\text { from the past. }\end{array}$ & $43 \%$ & $57 \%$ \\
\hline
\end{tabular}

\section{Recommendations}

To the institutions: Ministry of Education, Sport and Youth and Universities.

Referring to this study, we recommend that in Albania it is necessary to conduct further studies on leadership, job satisfaction and emotional intelligence. This is based on the fact that these three components are very important in the progress and success of a school.

On the other hand, it is necessary to train the principals about the latest news in the field of education, ethics, communication and leadership with a focus on raising leadership within the focus of Emotional Intelligence. It is important for them to be trained and informed about the use of various instruments to help the use of Emotional Intelligence to achieve institutional objectives. Educational institutions should help leaders with skills that meet today's challenges in running the school, in order to achieve success and this achievement will increase the results of the student.

The Ministry of Education, Sport and Youth should take initiatives for the professional development of principals, by designing policies that encourage the capacity development for teachers and school leaders in the country to guarantee in this form the success of educational institutions. Undoubtedly, knowledge and skills on Emotional Intelligence should be part of it as one of the most effective strategies to achieve success in running the school.

Principal and teachers

Based on the primary concept of Emotional Intelligence, enhancing job satisfaction and success, principals have a great responsibility in creating a positive school climate in order to achieve their goals.

This study showed that $70 \%$ of principals possess social skills, while about $53 \%$ are able to understand the feelings and emotions of teachers in school and try to support them. This shows that they can 
create a positive environment that leads to better teaching performance and as a consequence a higher student performance and hence unavoidably achieving their own school goals.

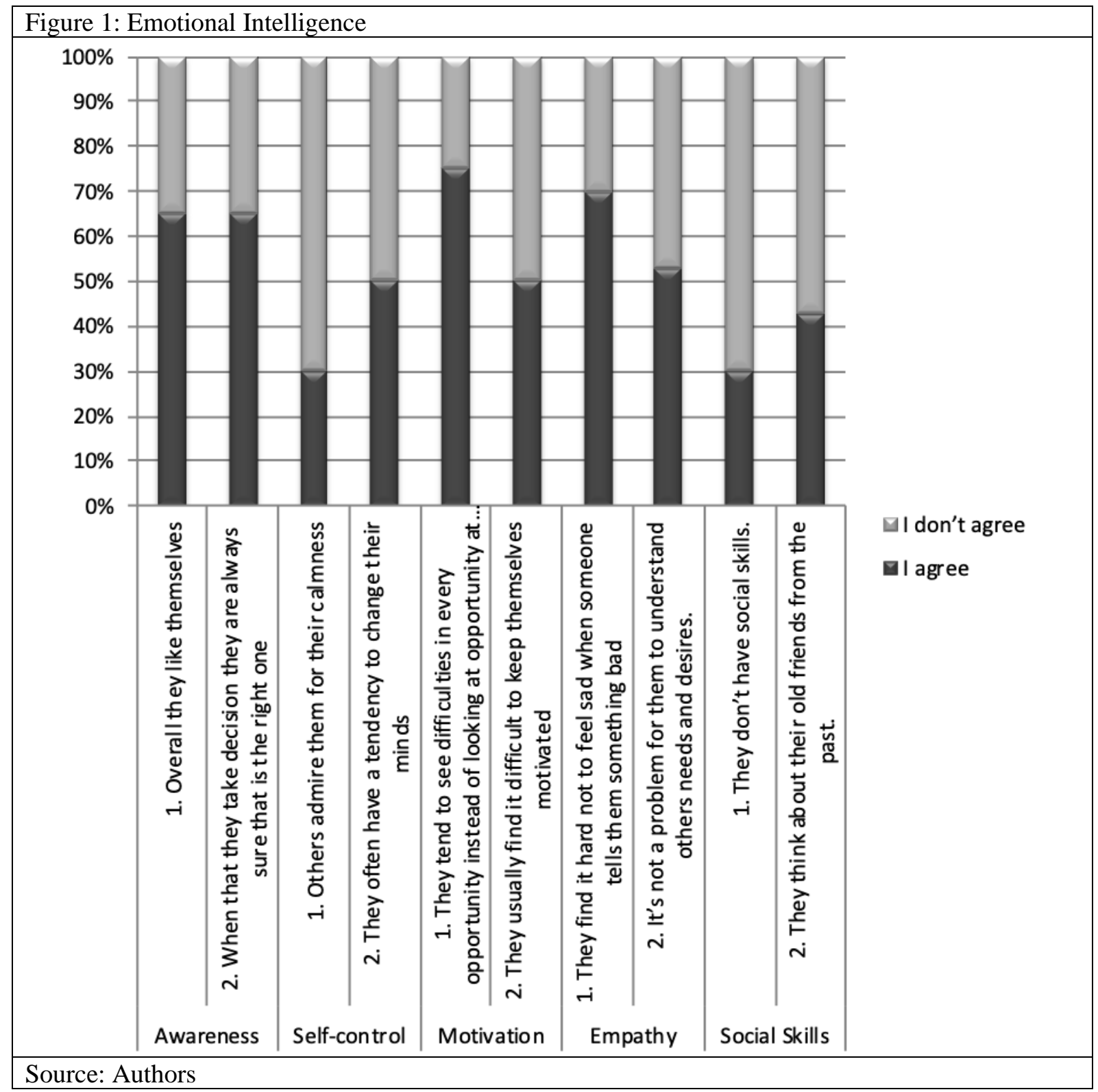

Also, directors, in the institution that they lead, can conduct mini-studies where they measure whether teachers are satisfied with their work or not and if not where the problems lie. These studies generate important data for the leader and provides the opportunity for improvement and change in the leadership style or other elements, to improve the work environment.

This change in leadership will help teachers become familiar with Emotional Intelligence as a concept and its importance in the success of work performance. They can then use Emotional Intelligence to improve teaching, motivate students, involve parents in closer partnership with the school, and more. Teachers who know and use Emotional Intelligence can teach students to develop and use elements of soft skills, which are very important for individual success in society such as: empathy, selfawareness, motivation, high social communication skills, etc. these are very important in the global society where we live.

\section{Conclusions}

At the end of this study we can conclude that leadership is very important in the achievement and the performance of an educational institution. Depending on the institutional dynamics, context or conditions, a particular management style may be preferred. A very important element in leadership is 
the ability of the leader to understand both social and emotional dynamics within the staff and to have the abilities to enable the use of these emotions in achieving educational objectives.

The results of this study show that in most cases this does not happen, managers lack the ability to understand and read the emotional side of their employees and consequently cannot use them to motivate and achieve institutional annual goals. Even in those cases where the manager exhibits empathy traits, related to the cultural context, it is not noticed that they are used to motivate and accomplish the objectives set by the director in their goals and their implementation.

The teaching profession is distinguished by the state of burnout, as a result of the hard work that teachers have to do with motivating students, enhancing partnerships with parents and the community. They also should take care of their feelings and emotions, as this balance affects the direct work they have with the students, with learning and motivating. This task belongs to school directors and this study found that $90 \%$ of principals are not capable of managing emotions and as a result they cause tension and nervousness in staff rather than being supportive and motivational which are important characteristics in a leader.

The results of this study show that school principals lack knowledge of Emotional Intelligence and the tools it provides for better staff management and motivation. Emotional intelligence and its features appear intuitively to school principals who are currently in a young age, even though they do not use it as a strategic way of successfully developing the institution.

There is a tendency to use EI characteristics from younger executives than those directors with more years of experience. These changes are not massive, but it is noted that younger executives possess some soft skills as an instrument of emotional intelligence. It should be noted that these skills appear unconsciously in most cases or as broader knowledge in the field of psychology and communication that young executives have. These characteristics are not intended to realize and achieve the success of institutional achievements but come as ethical behaviors and a desire to hear the teachers' needs. This is also due to the fact that in all the trainings provided by the leaders they do not receive knowledge about EI and its importance in the success of a school; on the contrary the term Emotional Intelligence is almost unknown.

\section{References}

Babu, B. P., Vaitla., S. R. (2013). Emotional intelligence of school teachers. International Journal of Education and Management Studies.

Coons, A.E, . Stogdill, R. M, . (1959) Leader behavior: Its description and measurement. Columbus: Bureau of Business Research, Ohio State University.

Ekman, P. (1973). Universal facial expressions in emotion. Studia Psychologica, XV (2): 140-147.

Ekman, P. (1982). Emotion in the human face. NewYork: Cambridge University Press.

Fullan, M. (2010) Forcat e ndryshimit, (Change Force). CDE. Tiranë

Gardner, H. (1983). Frames of mind. New York: Basic Books.

Gardner, W. \& Martinko, M. (1996). Using the Meyers-Briggs: Type Indicator to study managers: A literature review and research agenda. Journal of Management, 22(1):45-83.

Goleman, D. (1995). Emotional intelligence. New York: Bantam Books.

Goleman, G. Boyatzis. R \& McKee. A. (2002) Primal leadership: Realizing the power of emotional intelligence. Boston, MA: Harvard Business School Press.

Matthews, G., Zeidner, M., Roberts, R. D. (2007). The Science of emotional intelligence: Knowns and unknowns. Oxford University Press.

Mersino, A. C. (2013). Emotional intelligence for project managers. The people skills you need to achieve outstanding results; American Management Association. (2nd edition)

Ngozi, S. A,. Richards E.E,. Barnabas E. N, . Solomon A. A, . (2014). Influence of emotional intelligence and gender on job satisfaction among local government employees; Vol. 2 No. 4, 86-89; DOI: 10.12691/rpbs-2-4-2

Papathahasiou, S., \& Siati, M. (2014). Emotional intelligence and job satisfaction in greek banking sector. Greece: Research in Applied Ecnomics Vol. 6, No. 1.

Rathore, D., Chadha, N. K. et al. (2017) Emotional intelligence in the workplace. Indian Journal of Positive Psychology.

Urch Druskat. V., Sala. F., Mount. G. (2006). Linking emotional intelligence and performance at work: Current research evidence with individuals and groups. Lawrence Erlbaum Associates.

Zimmerman, A. (2013, May 28). What is emotional intelligence? Relationship Management. Aitp. 